\title{
Effects of a methanolic fraction of soybean seeds on the transcriptional activity of peroxisome proliferator-activated receptors (PPAR)
}

\author{
V.S. Carrara ${ }^{1}$, A.A. Amato², F.A.R. Neves ${ }^{2}$, R.B. Bazotte ${ }^{1}$, J.M.G. Mandarino², \\ C.V. Nakamura1 ${ }^{1}$, B.P.D. Filho ${ }^{1}$ and D.A.G. Cortez ${ }^{1}$ \\ 1'Departamento de Farmácia e Farmacologia, Universidade Estadual de Maringá, Maringá, PR, Brasil \\ ${ }^{2}$ Departamento de Farmacologia Molecular, Universidade de Brasília, Brasília, DF, Brasil \\ ${ }^{3}$ Empresa Brasileira de Pesquisa Agropecuária, Londrina, PR, Brasil
}

Correspondence to: D.A.G. Cortez, Departamento de Farmácia e Farmacologia, Universidade Estadual de Maringá, 87020-900 Maringá, PR, Brasil

Fax: +55-44-3261-4999. E-mail: dagcortez@uem.br

Since the anti-inflammatory, antidiabetic and hypolipidemic effects of soy isoflavones may be mediated by activation of peroxisome proliferator-activated receptors (PPAR), the present study investigated whether the methanolic fractions obtained from soybean seeds (E1) and soybean seed coats with hypocotyls (E2) could influence PPAR $\alpha$ PPAR $\gamma$ and PPAR $\beta / \delta$ transcriptional activity. The isoflavones from E1 and E2 were quantified by HPLC analysis. E1 and E2 were rich in isoflavones (daidzin, glycitin, genistin, malonyldaidzin, malonylglycitin, malonylgenistin, daidzein, glycitein, and genistein). Moreover, E1 and E2 showed no evidence of genetically modified material containing the gene CP4 EPSPS. To investigate PPAR transcriptional activity, human promonocytic $U-937$ cells were treated with $E 1$ and $E 2(200,400,800$, and $1600 \mu \mathrm{g} / \mathrm{mL})$, positive controls or vehicle. Data are reported as fold-activation of the luciferase reporter driven by the PPAR-responsive element. Doseresponse analysis revealed that $E 1$ and $E 2$ induced the transcriptional activity of PPAR $\alpha(P<0.001)$, with activation comparable to that obtained with $0.1 \mathrm{mM}$ bezafibrate (positive control) at $1600 \mu \mathrm{g} / \mathrm{mL}$ (4-fold) and $800 \mu \mathrm{g} / \mathrm{mL}$ (9-fold), respectively. In addition, dose-response analysis revealed that $E 1$ and $E 2$ activated PPAR $\beta / \delta(P<0.05)$, and the activation at $800 \mu \mathrm{g} / \mathrm{mL}(4-$ and 9-fold, respectively) was comparable to that of $0.1 \mathrm{mM}$ bezafibrate (positive control). However, no effect on PPAR $\gamma$ was observed. Activation of PPAR $\alpha$ is consistent with the lipid-lowering activity of soy isoflavones in vivo, but further studies are needed to determine the physiological significance of PPAR $\beta / \delta$ activation.

Key words: Isoflavones; Nuclear receptors; Soybean; PPAR $\alpha$ PPAR $\gamma$, PPAR $\beta / \delta$

Research supported by CNPq.

Received July 19, 2008. Accepted March 25, 2009

\section{Introduction}

Dietary soy has been shown to improve serum lipid levels, glycemic control and atherosclerosis in many animal models of obesity and insulin resistance (1). Clinical studies have also suggested the lipid-lowering effects of soy protein consumption in humans (2). However, the specific components of soy and the mechanisms underlying these beneficial effects are still a matter of controversy and remain to be identified (1).

Dietary soy components include protein, lipids, fiber, and phytochemicals, such as isoflavones, which have been identified as bioactive agents and widely recognized as estrogen receptor agonists or phytoestrogens $(3,4)$. Although this activity has been implicated in the atheroprotective effects of isoflavones, it has been increasingly accepted that these phytochemicals might activate other nuclear receptors regulating lipid metabolism, such as 
liver $\mathrm{x}$ receptor, farsenoid $\mathrm{x}$ receptor and peroxisome proliferator-activated receptors (PPARs) (1).

PPARs are members of the nuclear hormone receptor superfamily of ligand-activated transcription factors and regulate the expression of target genes involved in several physiological processes (5). Three receptor subtypes have been identified in mammals, namely PPAR $\alpha, \operatorname{PPAR} \beta / \delta$ and PPAR $\gamma$, with overlapping tissue distribution and functions. PPAR $\alpha$ is expressed in high levels in the liver, kidney and heart, PPAR $\gamma$ is largely expressed in adipose tissue and PPAR $\beta / \delta$ is ubiquitously expressed (6).

PPAR $\alpha$ controls the transcription of many genes involved in the catabolism of lipids, and this explains its hypolipidemic effects (7). Activation of PPAR $\gamma$ increases insulin sensitivity and appears to be a favorable factor in the treatment of insulin resistance associated with type 2 diabetes (8). In contrast to PPAR $\alpha$ and PPAR $\gamma$, the physiological role of PPAR $\beta / \delta$ is not fully known (9). It has been suggested that the anti-inflammatory, antidiabetic and hypolipidemic effects of soy isoflavones may be mediated by activation of PPAR $\alpha$ and PPAR $\gamma(10-12)$. However, little is known about the possibility of activation of PPAR $\beta / \delta$ with soy isoflavones. Therefore, in the present study, we investigated whether the methanolic fractions of soybean rich in isoflavones could activate PPAR $\beta / \delta$.

\section{Material and Methods}

\begin{abstract}
Material
Soybean seeds and soybean seed coats with hypocotyl fragments were obtained from the COAMO Company (Brazil). The seed coats were obtained as an industrial residue resulting from oil extraction from the seed. Isoflavone standards were purchased from Sigma (USA) and Fuji Co. (Japan). Human promonocyte U937 cells were obtained from Cells Culture Facility (University of California, USA). RPMI-1640 medium was obtained from Gibco (USA). Lysis buffer and the kit for testing luciferase activity were purchased from Promega (USA). Bezafibrate and troglitazone were purchased from Sigma, and rosiglitazone was purchased from Cayman Chemicals (USA). The expression vectors for PPAR $\alpha, \operatorname{PPAR} \alpha \beta / \delta$ and PPAR $\alpha \gamma$ and the plasmid containing the luciferase reporter driven by $a$ PPAR-responsive element were kindly provided by $\mathrm{J}$. Magae (Japan). The plasmid construction has been described (13).
\end{abstract}

\section{Analysis of transgenic soy}

Genetically modified herbicide-tolerant soy varieties contain the CP4 EPSPS gene that encodes 5-enolpyruvylshikimate-3-phosphate synthase from Agrobacte- rium spp strain $\mathrm{CP} 4$. This gene confers resistance to herbicides containing glyphosate. The presence of transgenic soybean was investigated using the Trait Crop and Grain Testing kit from Strategic Diagnostics Inc. (USA), as recommended by the manufacturer. Conventional nongenetically modified soybean seeds and soybean seeds containing the EPSPS gene were used as negative and positive controls, respectively. Transgenic grains were provided by the Monsanto Company (USA). These tests were authorized by the National Technical Commission for Biosafety (Certificate of Quality on Biosafety, CQB \#0002/ 96) and carried out at Embrapa Soybean (Brazil).

\section{Extraction of isoflavones from soybean}

One kilogram of frozen soybean seeds (E1) and soybean seed coats with hypocotyl fragments (E2) were triturated and macerated with $12 \mathrm{~L}$ hexane for 20 days and filtered. The residues E1 (702 g) and E2 (969 g) were macerated with ethanol:water $(3: 2 \mathrm{v} / \mathrm{v})$ for seven days and filtered. The solvent from the extracts was evaporated under reduced pressure and the lyophilized extract yielded 160.6 and $194.0 \mathrm{~g}$ ethanol extracts $\mathrm{E} 1$ and $\mathrm{E} 2$, respectively. The ethanol extracts were mixed with $90 \mathrm{~mL}$ methanol and centrifuged. The methanol fractions were evaporated to provide 48.0 and $26.7 \mathrm{~g}$ of the methanol fraction of $\mathrm{E} 1$ and $\mathrm{E} 2$, respectively.

\section{High-performance liquid chromatography}

Isoflavones from both methanolic fractions $(100 \mathrm{mg})$ were extracted using a $70 \%$ water-ethanol solution $(w / w)$ containing $0.1 \%$ acetic acid at room temperature. Tubes containing the samples were shaken every $15 \mathrm{~min}$ and after $1 \mathrm{~h}$ the extracts $(1.5 \mathrm{~mL})$ were centrifuged at 14,000 rpm for $15 \mathrm{~min}$ at $5^{\circ} \mathrm{C}$. The supernatant was then filtered $(0.45 \mu \mathrm{m})$ and $20 \mu \mathrm{L}$ of each sample was used for highperformance liquid chromatography (HPLC) analysis.

HPLC analysis of isoflavones was performed on an ODS C18 column (YMC Pack ODS-AM $250 \times 0.4$ mm ID, $5.0 \mu \mathrm{m}$ particle size, Japan) in a Waters 2690 HPLC system with an auto sampler and a photodiode array detector (Waters 996, USA). The wavelength was adjusted to $260 \mathrm{~nm}$. A binary gradient solvent system was employed. The mobile phases were: a) acidified methanol $(0.025 \%$ trifluoroacetic acid, TFA) and b) acidified Milli-Q water $(0.025 \%$ TFA). The initial composition of the gradient was $20 \%$ solvent A system, reaching $100 \%$ A after 40 min, and then returning to $20 \% \mathrm{~A}$ at $45 \mathrm{~min}$ and maintaining this condition up to $60 \mathrm{~min}$. The flow rate was $1 \mathrm{~mL} / \mathrm{min}$, with a column temperature of $25^{\circ} \mathrm{C}$. Isoflavones were adequately separated within $60 \mathrm{~min}$. Separated compounds were identified by comparison of retention times and UV spectra with 
isoflavone standards (glycoside and aglycon forms). Isoflavones were quantified using external standardization method (peak areas), and molar extinction coefficient for malonyl and acetyl forms (14).

\section{Cell culture and transient transfection assays}

Human promonocytic U-937 cells were maintained and subcultured in RPMI-1640 medium (Invitrogen ${ }^{\circledR}$, USA) supplemented with $10 \%$ fetal bovine serum, penicillin (50 IU/ $\mathrm{mL}$ ) and streptomycin $(50 \mu \mathrm{g} / \mathrm{mL})$, at $37^{\circ} \mathrm{C}$ and $5 \% \mathrm{CO}_{2}$. For transient transfection assays, cells were collected by centrifugation and resuspended in phosphate-buffered saline (PBS) containing calcium and dextrose $(1.5 \mathrm{~mL} x$ $10^{7}$ cells/0.5 mL PBS).

The cells were cotransfected with the expression vectors for PPAR $\alpha,-\beta / \delta$ or $-\gamma(1.5 \mu \mathrm{g})$ and a PPAR-responsive luciferase reporter vector (DR1-TK-Luc) by electroporation using a gene pulser (Bio-Rad ${ }^{\circledR}$, USA) at $300 \mathrm{mV}$ and $950 \mu \mathrm{F}$. Electroporated cells were then transferred to fresh RPMI-1640 medium and plated onto 12-well dishes $(1 \mathrm{~mL} /$ well) and treated in triplicate with the methanolic fraction of soybeans containing isoflavones $(200,400,800$, and 1600 $\mu \mathrm{g} / \mathrm{mL}$ ), bezafibrate (positive control for PPAR $\alpha$ and $-\beta / \delta$ transcriptional activity), troglitazone or rosiglitazone (positive control for PPAR $\gamma$ transcriptional activity) or vehicle (ethanol/DMSO, 1:1). After $24 \mathrm{~h}$, cells were collected by centrifugation, lysed by the addition of $150 \mu \mathrm{L} 1 \mathrm{X}$ lyses buffer (Promega ${ }^{\circledR}$, USA) and assayed for luciferase activity using a Luciferase Assay Kit from Promega ${ }^{\circledR}$ and a luminometer (Perkin Elmer ${ }^{\circledR}$, USA).

Data are reported as fold-activation of the luciferase reporter driven by the PPAR-responsive element calculated as the ratio of luciferase activity obtained in cell samples treated with the different compounds divided by luciferase activity obtained with vehicle. All experiments were performed at least three times in triplicate.

\section{Statistical analysis}

The results of the transient transfection assays are reported as means \pm SEM. Statistical significance was determined by analysis of variance (ANOVA) followed by the Newman-Keuls multiple comparison test, using the GraphPad Prism software for Windows, version 3.0 (USA). A P value $<0.05$ was considered to be statistically significant.

\section{Results}

\section{Analysis of transgenic soy}

Genetically modified soy containing the CP4 EPSPS gene was not detected in any of the samples (data not shown).
Analysis of the methanolic fractions of soybean seeds and soybean seed coats with hypocotyls (HPLC-UV analysis)

The methanolic fractions of soybean seeds (Figure 1A) and soybean seed coats and hypocotyls (Figure 1B) were analyzed for isoflavone composition by HPLC using standard compounds for comparison. The isoflavone composition of both types of soy are given in Table 1. Most of the isoflavones found in the soybean seeds were malonyl-
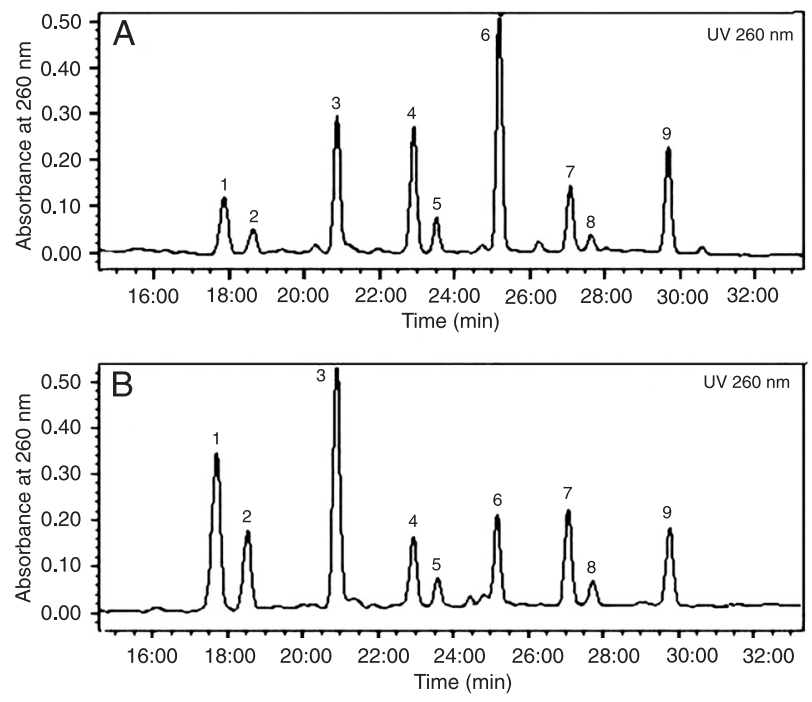

Figure 1. High-performance liquid chromatography (HPLC) profile of the methanolic fractions of soybean seeds (A) and soybean seed coats with hypocotyls (B). Compounds are: 1 , daidzin; 2, glycitin; 3, genistin; 4, malonyldaidzin; 5, malonylglycitin; 6, malonylgenistin; 7, daidzein; 8, glycitein; 9, genistein. Chromatographic conditions: column Metasil ODS C18 (250 x $0.4 \mathrm{~mm} \mathrm{ID,}$ $5.0 \mu \mathrm{m}$ ); linear gradient of methanol [0.025\% TFA (solvent A)], water [0.025\% TFA (solvent B)], 0-40 min: $20-100 \%$ A, at a flow rate of $1.0 \mathrm{~mL} / \mathrm{min}$; room temperature; injection $20 \mu \mathrm{L}$; detection: $260 \mathrm{~nm}$. The concentration injected for methanolic fractions (A and B) was about $66.6 \mathrm{mg} / \mathrm{mL}$.

Table 1. Isoflavone composition of the methanolic fractions of soybean seeds and seed coats with hypocotyls.

\begin{tabular}{lrc}
\hline & Soybean seeds & Seed coats with hypocotyls \\
\hline 1. Daidzin & $145.67 \pm 3.14$ & $393.78 \pm 5.39$ \\
2. Glycitin & $47.69 \pm 1.86$ & $149.41 \pm 1.52$ \\
3. Genistin & $147.54 \pm 5.54$ & $296.14 \pm 4.14$ \\
4. Malonyldaidzin & $276.54 \pm 4.21$ & $152.29 \pm 3.38$ \\
5. Malonylglycitin & $105.73 \pm 1.17$ & $89.11 \pm 3.94$ \\
6. Malonylgenistin & $466.54 \pm 7.37$ & $161.80 \pm 2.82$ \\
7. Daidzein & $57.73 \pm 1.26$ & $86.64 \pm 0.93$ \\
8. Glycitein & $22.61 \pm 0.36$ & $33.92 \pm 1.08$ \\
9. Genistein & $75.04 \pm 1.61$ & $55.84 \pm 0.82$ \\
Total isoflavones & 1345.09 & 1418.93
\end{tabular}

Data are reported as $\mathrm{mg}$ isoflavones in $100 \mathrm{~g}$ methanolic fraction and as the means \pm SD value of three determinations. 
daidzin, malonylglycitin and malonylgenistin (Table 1). On the other hand, most of the isoflavones found in the soybean seed coats with hypocotyls were daidzin, glycitin and genistin (Table 1).

Effect of increasing concentrations of a methanolic extract rich in conjugated and non-conjugated soybean isoflavones on PPAR $\alpha$ transcriptional activity

Dose-response analysis revealed that the methanolic fraction from soybean seeds and soybean seed coats with hypocotyls induced the transcriptional activity of PPAR $\alpha$, with activation comparable to that obtained with $0.1 \mathrm{mM}$ bezafibrate at $1600 \mu \mathrm{g} / \mathrm{mL}$ (Figure 2A) and $800 \mu \mathrm{g} / \mathrm{mL}$ (Figure 2B), respectively.
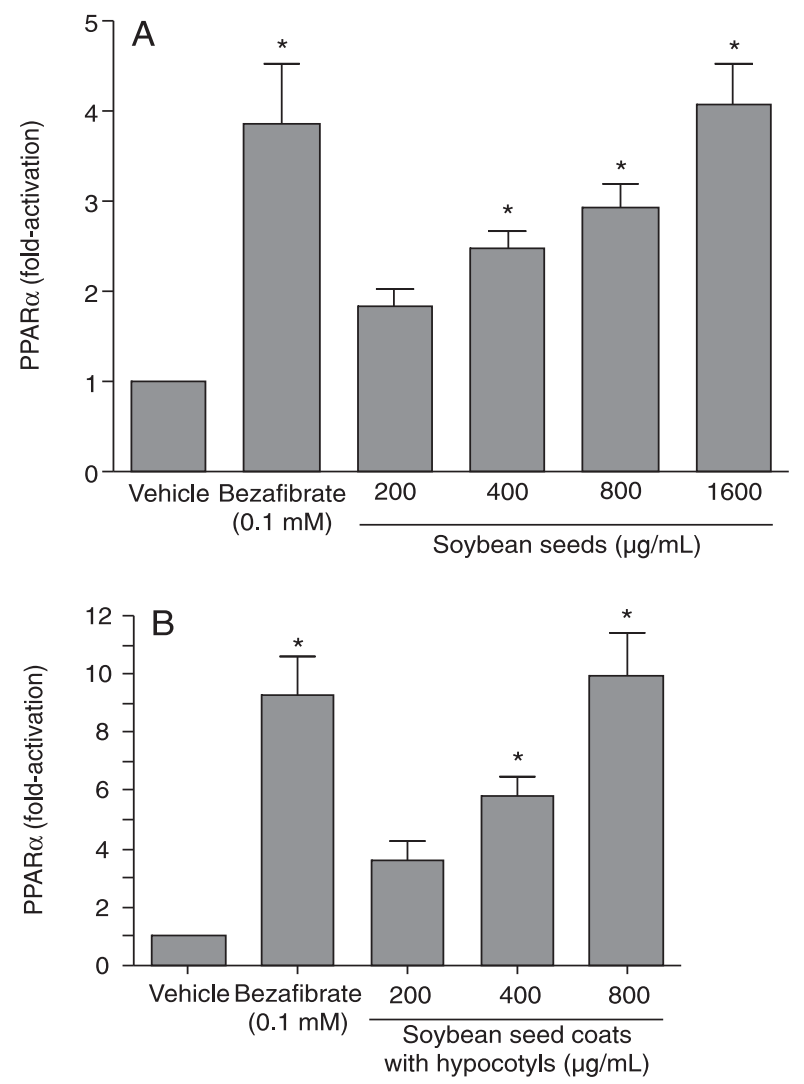

Figure 2. Activation of peroxisome proliferator-activated receptor alpha (PPAR $\alpha$ ) by the methanolic fraction of soybean seeds (Panel A) or soybean seed coats with hypocotyls (Panel B). U937 cells were cotransfected with the expression vector for PPAR $\alpha$ receptor and a luciferase reporter and then treated with vehicle (DMSO/ethanol, 1:1), bezafibrate or increasing amounts of the methanolic fraction of soybean seeds or soybean seed coats for $24 \mathrm{~h}$ and assayed for luciferase activity. Data are reported as means \pm SEM of fold-activation of PPAR $\alpha$. ${ }^{*} P<0.01$ vs vehicle (one-way ANOVA followed by the Newman-Keuls multiple comparison test).
Effect of increasing concentrations of a methanolic extract rich in conjugated and non-conjugated soybean isoflavones on PPAR $\gamma$ transcriptional activity

No activation of PPAR $\gamma$ was detected with any of the concentrations tested of the methanolic fraction from soybean seeds (Figure $3 \mathrm{~A}$ ) or with the methanolic fraction from soybean seed coats with hypocotyls (Figure 3B). The positive controls $10 \mu \mathrm{M}$ troglitazone and $10 \mu \mathrm{M}$ rosiglitazone behaved as expected.

Effect of increasing concentrations of a methanolic extract rich in conjugated and non-conjugated soybean isoflavones on PPAR $\beta / \delta$ transcriptional activity

Dose-response analysis revealed that the methanolic
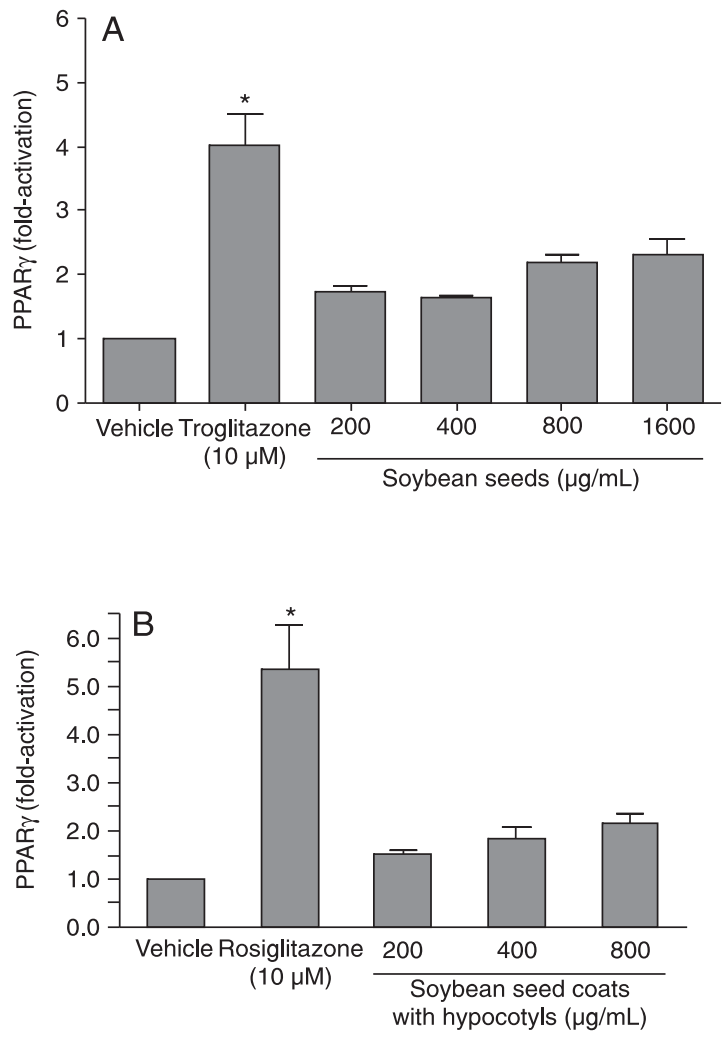

Figure 3. Activation of peroxisome proliferator-activated receptor gamma (PPAR $\gamma$ ) by the methanolic fraction of soybean seeds (Panel A) or soybean seed coats with hypocotyls (Panel B). U937 cells were cotransfected with the expression vector for the PPAR $\gamma$ receptor and a luciferase reporter and then treated with vehicle (DMSO/ethanol, 1:1), glitazone or increasing amounts of the methanolic fraction of soybean seeds or soybean seed coats for $24 \mathrm{~h}$ and assayed for luciferase activity. Data are reported as means \pm SEM of the fold-activation of PPAR $\gamma$. ${ }^{*} P<0.01$ vs vehicle (one-way ANOVA followed by the Newman-Keuls multiple comparison test). 
fraction from soybean seeds activated PPAR $\beta / \delta$, and the activation at $800 \mu \mathrm{g} / \mathrm{mL}$ was comparable to that of $0.1 \mathrm{mM}$ bezafibrate (Figure 4A). Similar results were obtained with $800 \mu \mathrm{g} / \mathrm{mL}$ of the methanolic fraction from soybean seed coats with hypocotyls (Figure 4B).

\section{Discussion}

The well-established beneficial effects of dietary soy on lipid metabolism and insulin sensitivity have been recently attributed to the activation of PPAR $\alpha$ and PPAR $\gamma$, respectively, by soy isoflavones $(1,8,10)$. However, little is known about the possibility that isoflavones activate PPAR $\beta /$ $\delta$, which plays a critical role in the regulation of metabolic homeostasis, and also in cardiac lipid metabolism $(15,16)$, fetal development (17), inhibition of human cancer cell line growth (18), protection against liver toxicity (19), modulation of inflammation $(6,20)$, and improved skeletal muscle oxidative enzyme activity in obese patients with type 2 diabetes mellitus (21).

In the present study, a methanolic fraction from soybean seeds and soybean seed coats with hypocotyls rich in conjugated soybean isoflavones was used to address the question of whether these soy fractions can activate PPAR $\beta / \delta$. For comparative purposes their effect on PPAR $\alpha$ and PPAR $\gamma$ was also investigated.

Our results indicated that the methanolic fractions rich in conjugated soybean isoflavones induced PPAR $\alpha$ and $\beta /$ $\delta$ transcriptional activity. Activation of PPAR $\alpha$ has been previously demonstrated in several other studies $(10,11,12$, 22). Unexpectedly, however, these fractions in the present study did not induce PPAR $\gamma$ transcriptional activity. A possible explanation for this result certainly depends of future studies with isolated isoflavones.

An important result is that the methanolic fractions rich in conjugated and non-conjugated soybean isoflavones used in this study activated PPAR $\beta / \delta$. To the authors' knowledge, this is the first demonstration that isoflavones activate PPAR $\beta / \delta$.

The effects of the methanolic fraction of soybean seeds and soybean seed coats with hypocotyls on PPAR $\alpha$ and PPAR $\alpha \beta / \delta$ transcriptional activity were similar although their composition in general terms were different. It is possible that the similar effects on both PPAR isoforms could be due to comparable concentrations of the isoflavones genistein and daidzein in the methanolic fractions of seeds and seed coats with hypocotyls. Further studies will indicate which soy isoflavone or mixtures of isoflavones activate PPAR $\alpha$ and PPAR $\beta / \delta$.

Taken together, our results are consistent with animal and clinical studies addressing the potential of isoflavones
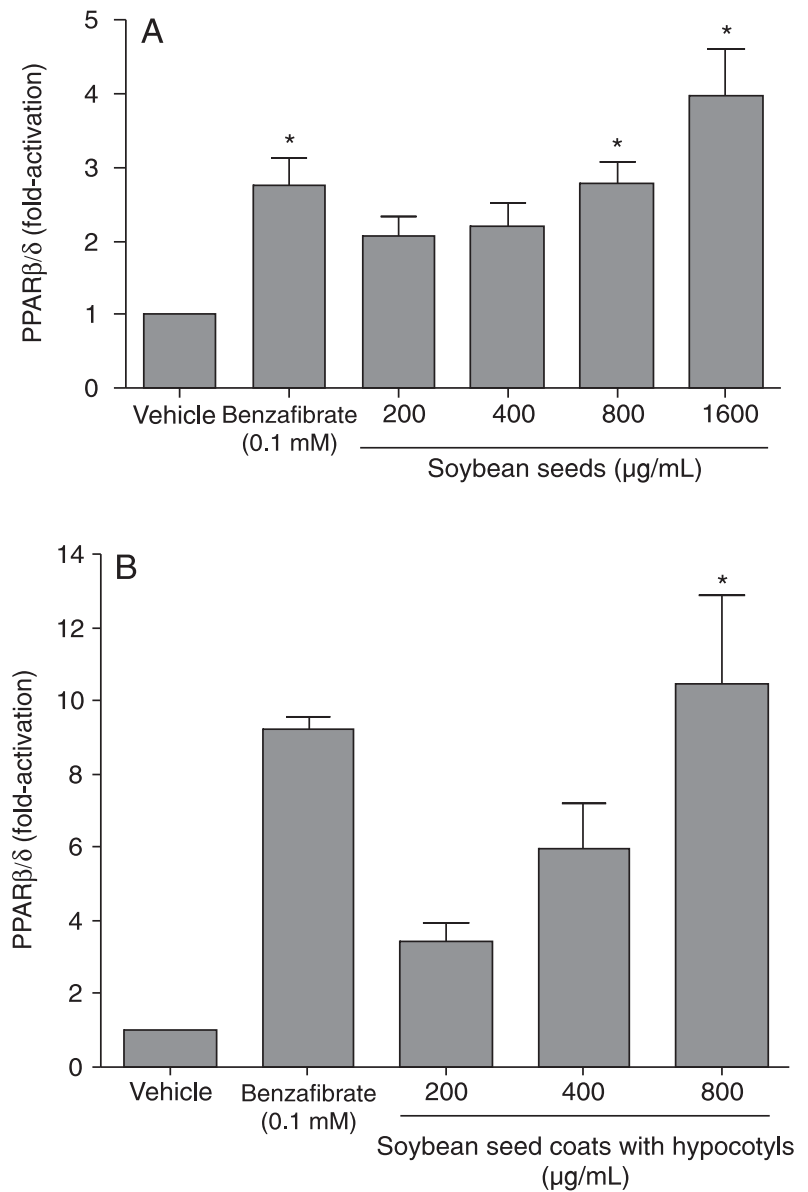

Figure 4. Activation of peroxisome proliferator-activated receptor $\beta / \delta(\operatorname{PPAR} \beta / \delta)$ by the methanolic fraction from soybean seeds (Panel A) or soybean seed coats with hypocotyls (Panel B). U937 cells were cotransfected with the expression vector for the $\mathrm{PPAR} \beta / \delta$ receptor and a luciferase reporter and then treated with vehicle (DMSO/ethanol, 1:1), bezafibrate or increasing amounts of the methanolic fraction of soybean seeds or soybean seed coats for $24 \mathrm{~h}$ and assayed for luciferase activity. Data are reported as means \pm SEM of the fold-activation of $\mathrm{PPAR} \beta / \delta$. ${ }^{*} \mathrm{P}<0.05$ vs vehicle (one-way ANOVA followed by the Newman-Keuls multiple comparison test).

as lipid-lowering $(8,10,11)$ and anti-inflammatory agents (12), and it can be expected that the methanolic extract from soybean seeds or seed coats with hypocotyls should promote lipid-lowering and anti-inflammatory effects.

Moreover, the observation that the methanolic extract from soybean seeds and from seed coats with hypocotyls activated PPAR $\alpha$ and PPAR $\beta / \delta$ but did not induce PPAR $\gamma$ transcriptional activity is important in view of the potential hepatotoxicity of PPAR $\gamma$ agonists. Furthermore, the possibility that the anti-inflammatory effects of soy isoflavones 
(12) could be mediated by PPAR $\beta / \delta$ receptors (6) must be considered. However, future in vivo studies will be necessary to determine the physiological significance of activation of both PPAR $\alpha$ and PPAR $\beta / \delta$.

\section{References}

1. Ricketts ML, Moore DD, Banz WJ, Mezei O, Shay NF. Molecular mechanisms of action of the soy isoflavones includes activation of promiscuous nuclear receptors. A review. J Nutr Biochem 2005; 16: 321-330.

2. Anderson JW, Johnstone BM, Cook-Newell ME. Meta-analysis of the effects of soy protein intake on serum lipids. $N$ Engl J Med 1995; 333: 276-282.

3. Obst JM, Seamark RF. Hormone studies on ewes grazing an oestrogenic (Yarloop clover) pasture during the reproductive cycle. Aust J Biol Sci 1975; 28: 279-290.

4. Wanda GJ, Starcke S, Zierau O, Njamen D, Richter T, Vollmer G. Estrogenic activity of griffonianone C, an isoflavone from the root bark of Millettia griffoniana: regulation of the expression of estrogen responsive genes in uterus and liver of ovariectomized rats. Planta Med 2007; 73: $512-518$

5. Aranda A, Pascual A. Nuclear hormone receptors and gene expression. Physiol Rev 2001; 81: 1269-1304.

6. Kilgore KS, Billin AN. PPARbeta/delta ligands as modulators of the inflammatory response. Curr Opin Investig Drugs 2008; 9: 463-469.

7. Mandard S, Muller M, Kersten S. Peroxisome proliferatoractivated receptor alpha target genes. Cell Mol Life Sci 2004; 61: 393-416

8. Davis J, Higginbotham A, O'Connor T, Moustaid-Moussa N, Tebbe A, Kim YC, et al. Soy protein and isoflavones influence adiposity and development of metabolic syndrome in the obese male ZDF rat. Ann Nutr Metab 2007; 51: 42-52.

9. Shearer BG, Steger DJ, Way JM, Stanley TB, Lobe DC, Grillot DA, et al. Identification and characterization of a selective peroxisome proliferator-activated receptor beta/ delta (NR1C2) antagonist. Mol Endocrinol 2008; 22: 523529.

10. Mezei O, Banz WJ, Steger RW, Peluso MR, Winters TA, Shay N. Soy isoflavones exert antidiabetic and hypolipidemic effects through the PPAR pathways in obese Zucker rats and murine RAW 264.7 cells. J Nutr 2003; 133: 12381243.

11. Mezei O, Li Y, Mullen E, Ross-Viola JS, Shay NF. Dietary isoflavone supplementation modulates lipid metabolism via PPARalpha-dependent and -independent mechanisms. Physiol Genomics 2006; 26: 8-14.

12. Chacko BK, Chandler RT, D'Alessandro TL, Mundhekar A, Khoo NK, Botting N, et al. Anti-inflammatory effects of isoflavones are dependent on flow and human endothelial

\section{Acknowledgments}

The authors are grateful to C.E. Oliveira and S.C. Oliveira from State University of Maringá, Maringá, PR, Brazil, for their technical assistance during the experiments.

cell PPARgamma. J Nutr 2007; 137: 351-356.

13. Forman BM, Tontonoz $\mathrm{P}$, Chen J, Brun RP, Spiegelman BM, Evans RM. 15-Deoxy-delta 12, 14-prostaglandin J2 is a ligand for the adipocyte determination factor PPAR gamma. Cell 1995; 83: 803-812.

14. Berhow MA. Modern analytical techniques for flavonoid determination. Adv Exp Med Biol 2002; 505: 61-76.

15. Gilde AJ, van der Lee KA, Willemsen PH, Chinetti G, van der Leij FR, van der Vusse GJ, et al. Peroxisome proliferator-activated receptor (PPAR) alpha and PPARbeta/delta, but not PPARgamma, modulate the expression of genes involved in cardiac lipid metabolism. Circ Res 2003; 92: 518-524.

16. Sheng L, Ye P, Liu YX, Han CG, Zhang ZY. Peroxisome proliferator-activated receptor beta/delta activation improves angiotensin II-induced cardiac hypertrophy in vitro. Clin Exp Hypertens 2008; 30: 109-119.

17. Rees WD, McNeil CJ, Maloney CA. The roles of PPARs in the fetal origins of metabolic health and disease. PPAR Res 2008; 2008: 459030.

18. Girroir EE, Hollingshead HE, Billin AN, Willson TM, Robertson GP, Sharma AK, et al. Peroxisome proliferator-activated receptor-beta/delta (PPARbeta/delta) ligands inhibit growth of UACC903 and MCF7 human cancer cell lines. Toxicology 2008; 243: 236-243.

19. Shan W, Nicol CJ, Ito S, Bility MT, Kennett MJ, Ward JM, et al. Peroxisome proliferator-activated receptor-beta/delta protects against chemically induced liver toxicity in mice. Hepatology 2008; 47: 225-235.

20. Man MQ, Barish GD, Schmuth $M$, Crumrine $D$, Barak $Y$, Chang S, et al. Deficiency of PPARbeta/delta in the epidermis results in defective cutaneous permeability barrier homeostasis and increased inflammation. $J$ Invest Dermatol 2008; 128: 370-377.

21. Mensink M, Hesselink MK, Russell AP, Schaart G, Sels JP, Schrauwen P. Improved skeletal muscle oxidative enzyme activity and restoration of PGC-1 alpha and PPAR beta/ delta gene expression upon rosiglitazone treatment in obese patients with type 2 diabetes mellitus. Int J Obes 2007; 31: 1302-1310.

22. Kim S, Shin HJ, Kim SY, Kim JH, Lee YS, Kim DH, et al. Genistein enhances expression of genes involved in fatty acid catabolism through activation of PPARalpha. Mol Cell Endocrinol 2004; 220: 51-58. 